\title{
Aspectos clínicos e laboratoriais do complexo gengivite-estomatite em gatos domésticos
}

\author{
[Clinic and laboratorial profile of Gingivostomatitis Complex in domestic cats] \\ R.C.C. Barbosa ${ }^{1}$, C.B. Gitti ${ }^{2}$, M.C.N. Castro ${ }^{3}$, F. Mendes-de-Almeida ${ }^{3}$ \\ ${ }^{1}$ Aluno de pós-graduação - Universidade Federal Fluminense - Niterói, RJ \\ ${ }^{2}$ Universidade Federal Rural do Rio de Janeiro - Seropédica, RJ \\ ${ }^{3}$ Universidade Federal Fluminense - Niterói, RJ
}

\begin{abstract}
RESUMO
Foram incluídos 76 gatos domésticos com diferentes graus (I a IV) de lesões em cavidade oral, os quais foram avaliados clinicamente e tiveram coletadas amostras de sangue e suabes da cavidade oral. A maioria dos gatos portadores de CGE eram machos, castrados, adultos, sem raça definida e com estilo de vida confinado. Os sinais clínicos observados e associados à gravidade da inflamação na cavidade oral foram halitose $(98,7 \%)$; ptialismo $(22,4 \%)$; hemorragia bucal $(9,2 \%)$ e úlcera na parte superior dos lábios $(2,6 \%)$; desconforto à manipulação da cavidade oral $(44,7 \%)$ e perda dentária $(55,3 \%)$. A maioria dos gatos avaliados foi classificada no grau II (43,4\%). Não se observou diferença significativa nos resultados do eritrograma dos gatos portadores de CGE, independentemente da gravidade das lesões e da sintomatologia clínica. Entretanto, observou-se neutrofilia $(21,1 \%)$ e aumento de proteínas plasmáticas totais $(47,3 \%)$, na maioria dos animais de grau II, sugerindo que esses parâmetros laboratoriais, quando aumentados, possam estar associados a graus menos graves de CGE. A análise das lâminas de citologia da cavidade oral dos gatos demonstrou que a presença de Simonsiella spp. foi mais frequente nos animais incluídos no grau IV, entretanto não é possível afirmar que essa bactéria esteja relacionada à gravidade das lesões.
\end{abstract}

Palavras-chave: felinos, cavidade oral, graus de inflamação, sinais clínicos, análise laboratorial

\begin{abstract}
Seventy six domestic cats classified with different scores (I to IV) of oral lesions have been included in the study, being clinically examined and having blood samples and oral cavity swabs collected. Most cats diagnosed with Gingivostomatitis Complex (GSC) were male, neutered, adult, DSH, and lived confined. Clinical signs observed and related to the severity of mouth inflammation were halitosis (98.7\%), ptyalism (22.4\%), oral hemorrhage (9.2\%), and upper lip ulcers (2.6\%); discomfort during mouth examination (44.7\%) and tooth loss (55,3\%). Most cats have been classified as score II (43.4\%). The red blood cell count showed no significant statistical difference regardless the different scores of oral lesions and clinical symptoms. However, the leukogram showed neutrophilia (21.1\%) and plasmatic proteins had an increased level (47.3\%), in most of the animals classified as score II, suggesting that these parameters, when increased, may be associated to less severe GSC scores. Oral cavity microscope slides analysis showed that Simonsiella spp. have been more frequent in the cytology of the score IV animals, however, it does not allow us to correlate the presence of the bacteria with the severity lesions degree.
\end{abstract}

Keywords: feline, oral cavity, inflammation scores, clinical signs, laboratorial analysis

\section{INTRODUÇÃO}

O complexo gengivite-estomatite (CGE) é a segunda afecção oral mais frequentemente observada na rotina clínica (Niza et al., 2004;

Recebido em 11 de maio de 2017

Aceito em 9 de janeiro de 2018

E-mail: reneecristine@veterinaria.med.br
Allemand et al., 2013), com taxas de prevalência mundial variando de 0,7 a $12 \%$ (Healey et al., 2007; Harley et al., 2010; Winer et al., 2016). No Brasil, foram observadas prevalências variando de 11,7 a $16,6 \%$ (Venturini, 2006). É uma síndrome que acomete gatos de todas as idades, 
sendo mais grave nos animais mais idosos. Não apresenta predisposição sexual, e algumas raças parecem ser mais susceptíveis, como Abissínio, Birmanês, Siamês e Himalaia (Niza et al., 2004; Healey et al., 2007).

É caracterizado por uma inflamação intensa, de caráter úlcero-proliferativo, que acomete principalmente a região caudal da cavidade oral, podendo atingir a borda da gengiva, o arco glossopalatino, as fauces, os lábios e a língua (Niza et al., 2004; Milella, 2014; Winer et al., 2016). A etiologia dessa afecção não é totalmente esclarecida, mas acredita-se que possa ser causada ou potencializada por diversos fatores, como a presença de bactérias, vírus, alterações nutricionais ou de outras doenças da cavidade oral, além de um desequilíbrio no sistema imunológico (Abreu, 2012; Allemand et al., 2013). Embora alguns autores afirmem não haver predisposição racial (Lyon, 2005; Matilde et al., 2013), outros relatam que algumas raças parecem ser mais suscetíveis, como Siamês, Abissínio, Persa, Himalaia e Birmanês (Niza et al., 2004; Healey et al., 2007).

Muitos animais podem ser assintomáticos, embora a presença de halitose seja frequentemente observada. Outros sinais que acompanham a síndrome são: inapetência, ptialismo, desconforto, disfagia, perda de peso e desidratação (Healey et al., 2007; Winer et al., 2016). A saliva pode apresentar-se espessada, "em fios" - eventualmente, com estrias de sangue - e com odor fétido e costuma deixar vestígios na região labial (Matilde et al., 2013). Pode ocorrer sangramento gengival, pois os tecidos ficam friáveis. Muitos gatos apresentam o pelame seco e sem brilho, podendo desenvolver seborreia, uma vez que a autohigiene fica dificultada. Perda de dentes é observada com certa frequência, especialmente dos incisivos ou, ainda, lesão de reabsorção odontoclástica (Milella, 2014).

O diagnóstico é realizado com base na sintomatologia clínica e exige uma anamnese detalhada, que inclua informações sobre idade, tipo de alimentação, modo de vida do animal, progressão da afecção e doenças concomitantes. O exame da cavidade oral, geralmente, é difícil de ser realizado devido à dor intensa que o animal apresenta, sendo necessário, muitas vezes, realizar contenção química (Niza et al.,
2004; Matilde et al., 2013; Dokuzeylul e Kayar, 2016). Como as lesões tendem a se localizar com maior intensidade na região caudal, ao exame clínico, é possível observar aumento considerável dos linfonodos submandibulares (Healey et al., 2007; Matilde et al., 2013).

Na cavidade oral, as alterações são classificadas em quatro graus, de acordo com a gravidade do processo inflamatório. No primeiro grau, observam-se hiperemia gengival discreta e gengivite leve. Em geral, o animal não apresenta ptialismo, hemorragia ou desconforto. A halitose, no entanto, costuma estar presente em todos os graus. No segundo grau, a gengivite é moderada, a hiperemia se torna evidente, não ocorrendo, no entanto, hiperplasia e/ou ulceração. Alguns animais já começam a demonstrar sinais de desconforto à palpação. No terceiro grau, a gengivite é grave, com hiperemia evidente, hiperplasia e/ou ulceração. Nesse estágio, pode ocorrer perda de dentes. Pode ser observado desconforto, ptialismo e sangramento gengival. No quarto grau, a gengivite é muito grave, a hiperemia é intensamente evidente, ocorre hiperplasia e/ou ulceração gengival, perda de vários dentes, e os tecidos gengivais se encontram bastante friáveis, de modo que o sangramento gengival é frequente (Geraldo Júnior, 2010; Abreu, 2012).

Os exames complementares, embora nem sempre apresentem alterações significativas, devem ser solicitados, pois podem mostrar afecções sistêmicas concomitantes. Devem ser incluídos hemograma completo, perfil bioquímico (alanina aminotransferase (ALT), fosfatase alcalina, ureia, creatinina, proteínas totais, albumina, globulina e relação albumina-globulina), além de pesquisa de retrovírus, calicivírus e herpesvírus. Sugere-se, ainda, realizar radiografias de cavidade oral (Niza, 2004; Matilde et al., 2013; Milella, 2014). É importante que a bioquímica sérica inclua o proteinograma, pois grande parte dos gatos com CGE apresenta hiperproteinemia, devido à hipergamaglobulinemia (Niza et al., 2004; Lyon, 2005; Southerden e Gorrel, 2007).

O diagnóstico definitivo é por meio de exame histopatológico de amostra de biópsia da cavidade oral, e esse exame é sempre indicado quando as lesões forem assimétricas ou não responsivas ao tratamento, a fim de se eliminarem outras possíveis causas para as 
lesões, como tumores, afecções autoimunes, traumas por queimaduras ou ingestão de substâncias abrasivas, e complexo granulomaeosinofílico. O exame citológico é um teste de triagem rápido, minimamente invasivo, e útil para lesões de orofaringe, cujos resultados, muitas vezes, correlacionam-se com os achados histopatológicos, podendo ser realizado isolada ou concomitantemente à biopsia e/ou coleta de material biológico para cultura de bactérias e fungos (Bernreuter, 2009; Bonfanti et al., 2015).

Nas amostras contidas nas lâminas por impressão ou raspado da cavidade oral de animais hígidos, é comum observar a presença de bactérias, como Simonsiella spp. e bactérias espiraladas, neutrófilos em pequena quantidade, células epiteliais grandes, achatadas e redondas a ligeiramente angulares, com um citoplasma claro, abundante e um pequeno núcleo que apresenta a cromatina condensada. Já em gatos portadores de CGE, observa-se um infiltrado inflamatório caracterizado pela presença predominante de linfócitos maduros e plasmócitos, podendo haver, ainda, células inflamatórias dispersas (Bernreuter, 2009).

Tendo em vista a dificuldade dos clínicos de pequenos animais em estabelecer um diagnóstico precoce e baseado na sintomatologia clínica e em exames laboratoriais, este estudo teve por objetivo analisar o perfil populacional e estabelecer os principais aspectos clínicos e laboratoriais associados à gravidade das lesões em cavidade oral de gatos domésticos portadores de CGE.

\section{MATERIAL E MÉTODOS}

O estudo foi conduzido com a aprovação da Comissão de Ética no Uso de Animais (Ceua) da Universidade Federal Fluminense - UFF, sob o número 710. Os responsáveis foram informados sobre a pesquisa, e aqueles animais cujos responsáveis assinaram o termo de consentimento livre e esclarecido foram incluídos.

Foram incluídos gatos domésticos aleatoriamente, provenientes de abrigos, domicílios ou atendimento clínico, na região metropolitana do Rio de Janeiro, no período de agosto de 2015 a setembro de 2016, independentemente de sexo, raça ou idade, portadores de lesões na cavidade oral, características de complexo gengivite-estomatite (CGE). Foram excluídos animais com diagnóstico prévio de doença renal crônica (DRC), não cooperativos, de comportamento agressivo ou intensamente debilitados.

Informações como sexo, idade, estado reprodutivo, raça, estilo de vida (confinado ou livre), estado geral, escore de condição corporal, tipo de alimentação e frequência, ingestão de água e ocorrência de vômitos foram anotadas em fichas individuais. Os responsáveis foram questionados acerca de diagnóstico prévio de CGE, tempo do diagnóstico, exames complementares e tratamento.

A idade foi classificada em faixas etárias, segundo Vogt et al. (2010), sendo filhotes os gatos até seis meses; jovens, de sete meses a dois anos; adultos jovens, de três a seis anos; adultos, aqueles entre sete e 10 anos; idosos, os gatos entre 11 e 14 anos; e geriatras, os com mais de 15 anos.

Para avaliação do escore de condição corporal (ECC), utilizou-se a escala de cinco níveis de Lafflame, adaptada por Colliard et al., 2009, sendo 1 caquético, 2 magro, 3 normal, 4 sobrepeso e 5 obeso.

Realizou-se avaliação clínica completa, com inspeção, avaliação de padrão respiratório, palpação e olfação (da cavidade oral). A classificação do estado geral em "bom" e "alterado" levou em conta a aparência do animal, o pelame, o ECC, a hidratação e a cor das mucosas. No exame da cavidade oral, avaliou-se o local das lesões, se havia perda de dentes e, caso houvesse, quais dentes; ocorrência de ptialismo, halitose, hemorragia bucal, úlcera indolente, desconforto durante o exame e o grau das lesões. As lesões foram classificadas de acordo com a gravidade, utilizando-se uma escala adaptada de Waters et al. (1993), Geraldo Júnior (2010) e Abreu (2012), sendo: grau I: gengivite leve, hiperemia gengival discreta; grau II: gengivite moderada, hiperemia evidente, ausência de ulceração; grau III: gengivite grave, hiperemia evidente, hiperplasia e/ou ulceração; e grau IV: gengivite muito grave, hiperemia bastante evidente, hiperplasia e/ou ulceração gengival, tecidos gengivais friáveis. 
Após o exame clínico, o animal foi contido manualmente e coletaram-se até $3 \mathrm{~mL}$ de sangue por punção da veia cefálica ou femural. Foram realizados hemograma completo e bioquímica sanguínea (alanina aminotransferase (ALT), fosfatase alcalina, proteínas totais, albumina, globulina, relação albumina-globulina, ureia e creatinina). Coletaram-se amostras das lesões na cavidade oral, com auxílio de um suabe estéril, que foram encaminhadas para avaliação citológica.

Os dados de identificação dos animais e os resultados dos exames laboratoriais foram compilados e armazenados em planilhas no programa operacional Microsoft Excel (Microsoft ${ }^{\circledR}$ ). Os dados foram submetidos aos testes do qui-quadrado e de Fisher Exato, com grau de significância de $95 \%$.

\section{RESULTADOS}

Muitas são as alterações causadas pelo complexo gengivite-estomatite (CGE) na cavidade oral de gatos domésticos, levando a diversos graus de desconforto ao animal e interferindo em seus hábitos alimentares e de higiene.

A avaliação da cavidade oral de 76 gatos domésticos demonstrou que, em relação ao grau das lesões, baseado na gravidade da inflamação e demais sinais observados na cavidade oral, classificaram-se 26,3\% (20/76) dos animais no grau I; 43,4\% (33/76) no grau II; 26,3\% (20/76) no grau III; e 3,9\% (3/76) no grau IV.

Os sinais clínicos associados à gravidade da inflamação na cavidade oral dos gatos acometidos por CGE foram halitose $(98,7 \%$ 75/76); ptialismo (22,4\% - 17/76); hemorragia bucal $(9,2 \%$ - 7/76) e úlcera na parte superior dos lábios $\left(2,6 \%\right.$ - 2/76) $\left(x^{2}=202,64 ; \mathrm{P}=0,0001\right)$; desconforto à manipulação da cavidade oral $(44,7 \%$ - 34/76); e perda dentária $(55,3 \%$ 42/76), sendo $57,1 \%(24 / 42)$ de dentes incisivos; $7,1 \%$ (3/42) de incisivos e pré-molares; $7,1 \%$ (3/42) de incisivos, pré-molares e molares; $9,5 \%$ (4/42) de dentes molares; 2,4\% (1/42) de incisivos e caninos; $2,4 \%$ (1/42) de incisivos, caninos e molares; $11,9 \%$ (5/42) de dentes incisivos e molares; e um gato $(2,4 \%$ - 1/42) havia perdido todos os dentes $\left(x^{2}=90,88\right.$; $\mathrm{P}=0,0001$ ).
Entre os animais classificados no grau I (26,3\% 20/76), além de gengivite leve e hiperemia discreta, observou-se halitose em $95 \%$ (19/20). A maioria era macho $\left(60 \%\right.$ - 12/20) $\left(x^{2}=0,90\right.$; $\mathrm{P}=0,34)$, jovem $(7 / 20)$ ou adulto jovem $(40 \%$ $8 / 20) \quad\left(X^{2}=19,92 ; \mathrm{P}=0,0012\right)$, castrado $(80 \%$ 16/20) $\left(x^{2}=12,10 ; \mathrm{P}=0,0005\right)$; todos eram SRD $\left(x^{2}=36,50 ; \quad \mathrm{P}=0,0001\right), \quad 80 \% \quad(16 / 20) \quad$ viviam confinados $\left(x^{2}=12,10 ; \mathrm{P}=0,0005\right)$ e $45 \%(9 / 20)$ conviviam com, no máximo, outros cinco animais $\left(x^{2}=10,67 ; \mathrm{P}=0,0136\right)$.

A maioria dos gatos avaliados foi classificada no grau II (43,4\% - 33/76). Perda dentária foi observada em $54,5 \%$ dos animais (18/33), todos tinham halitose, e 45,5\% (15/33) apresentaram sinais de desconforto ao exame da cavidade oral. A maioria dos animais desse grupo era macho $(60,6 \%-20 / 33) \quad\left(x^{2}=2,18 ; \quad \mathrm{P}=0,13\right)$, adulto $(39,4 \%-13 / 33)\left(x^{2}=15,36 ; \mathrm{P}=0,0040\right)$, castrado $\left(93,9 \%\right.$ - 31/33) $\left(x^{2}=47,52 ; \mathrm{P}=0,0001\right)$; todos eram $\mathrm{SRD} \quad\left(x^{2}=62,06 ; \quad \mathrm{P}=0,0001\right), \quad 93,9 \%$ (31/33) viviam confinados $\left(x^{2}=47,52 \mathrm{P}=0,0001\right)$ e $63,6 \%(21 / 33)$ conviviam com outros 11 a 20 animais $\left(x^{2}=37,29 ; \mathrm{P}=0,0004\right)$.

Todos os animais avaliados no grau III apresentaram halitose; 95\% (19/20) apresentaram perda dentária, $45 \%$ (9/20) ptialismo e $75 \%$ (15/20) mostraram sinais de desconforto ao exame da cavidade oral. Hemorragia bucal foi observada em 30\% (6/20) dos animais. A maioria deles eram machos $\left(75 \%\right.$ - 15/20) $\left(x^{2}=8,10\right.$; $\mathrm{P}=0,004)$, adultos $(35 \%-7 / 20) \quad\left(x^{2}=9,84\right.$; $\mathrm{P}=0,079)$, castrados $\left(95 \%\right.$ - 19/20) $\left(x^{2}=28,90\right.$; $\mathrm{P}=0,0001), \quad \mathrm{SRD} \quad(95 \%-19 / 20) \quad\left(x^{2}=28,90\right.$; $\mathrm{P}=0,0001)$, viviam confinados (95\% - 19/20) $\left(x^{2}=28,90 ; \mathrm{P}=0,0001\right)$ e conviviam com 11 a 20 animais $(70 \%-14 / 20)\left(x^{2}=12,60 ; \mathrm{P}=0,00003\right)$ (Tab. 1).

Os três gatos classificados no grau IV apresentaram ainda halitose, ptialismo, dor à manipulação, perda dentária, e um gato apresentou também hemorragia bucal. Todos eram machos, castrados, dois eram idosos e um, 
geriatra. Todos viviam confinados, dois deles conviviam com outros 11 a 20 animais, e um com mais de 20 .

Um total de $90,8 \%(69 / 76)$ dos gatos era alimentado com alimento seco e úmido, enquanto 9,2\% (7/76) recebiam apenas alimento seco $\left(x^{2}=97,92 ; \mathrm{P}=0,00001\right)$. Com relação à frequência da alimentação, 17,1\% (13/76) dos gatos eram alimentados duas vezes ao dia; $7,9 \%$ (6/76), três vezes ao dia; $2,6 \%$ (2/76), quatro vezes ao dia; e $72,4 \%$ (55/76) tinham acesso ao alimento à vontade $\left(x^{2}=125,61 ; \mathrm{P}=0,0001\right)$.

Com relação à avaliação clínica dos animais classificados no grau I, todos apresentaram bom estado geral, $70 \%(14 / 20)$ com ECC 3 $\left(x^{2}=440,63 ; \quad \mathrm{P}=0,0001\right)$, todos normofágicos $\left(x^{2}=60,0 ; \mathrm{P}=0,0001\right)$, sem episódios de vômito e com pelame sem alterações. Dos animais classificados no grau II, a maioria apresentou bom estado geral $(87,9 \%$ - 29/33), ECC 3 (57,6\% - 19/33) $\left(x^{2}=45,68 ; \mathrm{P}=0,0001\right)$, normofagia $\left(93,9 \%\right.$ - 31/33) $\left(x^{2}=81,82 ; \mathrm{P}=0,0001\right)$; não se observaram episódios de vômito $(87,9 \%$ - 29/33) $\left(x^{2}=34,91 ; \mathrm{P}=0,0001\right)$ e a maioria apresentou pelame sem alterações $(90,9 \%$ - 30/33). Entre os animais do grau III, todos apresentaram bom estado geral, $60 \%(12 / 20)$ foram classificados no ECC $3 \quad\left(x^{2}=42,12 ; \quad \mathrm{P}=0,0001\right), 95 \% \quad(19 / 20)$ estavam normofágicos $\left(x^{2}=50,52 ; \mathrm{P}=0,0001\right)$, $35 \%(7 / 20)$ apresentaram episódios de vômito $\left(x^{2}=2,50 ; \mathrm{P}=0,11\right)$ e $95 \%(19 / 20)$ estavam com o pelame normal. Dos três animais com grau IV, dois apresentaram bom estado geral, ECC 3, normofagia, e um deles apresentou episódios de vômito e pelame alterado. $\mathrm{O}$ outro gato apresentou estado geral alterado, ECC 2, hipofagia e pelame alterado.

Dos animais diagnosticados previamente com CGE (19,7\% - 15/76), 80\% (12/15) receberam algum tipo de tratamento. Nenhum estava em tratamento no momento da coleta. Desses, dois $(16,7 \%)$ foram incluídos no grau II; oito $(66,6 \%)$ no grau III; e dois $(16,7 \%)$ no grau IV. Embora sem diferença estatística, a maioria dos gatos previamente diagnosticados com CGE que haviam sido tratados pertenciam ao grupo de grau III de lesão em cavidade oral $\left(x^{2}=9,00\right.$; $\mathrm{P}=0,011)$.

Quanto aos resultados do eritrograma, dos 20 animais classificados no grau I, apenas um animal apresentou anemia. Dos 33 animais de grau II, também um animal apresentou anemia. A concentração de hemoglobina corpuscular média se mostrou baixa em cinco dos animais e alta em um gato. A hematimetria dos 20 gatos com grau III mostrou anemia em dois dos animais. Nenhum dos animais de grau IV apresentou alterações no eritrograma. Não se observou diferença estatística no eritrograma dos gatos incluídos nos diferentes graus de lesão em cavidade oral $\left(x^{2}=1,40 ; \mathrm{P}=0,7056\right)$.

Relativamente ao leucograma, a maioria dos gatos apresentou valores dentro da normalidade, entretanto houve aumento no valor global em $21,1 \%$ (16/76) dos animais avaliados, sendo $12,5 \%(2 / 20)$ classificados no grau I; $57,0 \%$ (9/33) no grau II; $18,7 \%$ (3/20) no grau III; e $13,7 \%(2 / 3)$ no grau IV $\left(x^{2}=8,97 ; \mathrm{P}=0,0296\right)$. Observou-se aumento no valor absoluto de segmentados em 25\% (19/76) dos animais (Tab. 1).

Aproximadamente metade (47,3\% - 36/76) dos gatos apresentou aumento nos valores de proteínas plasmáticas totais (PPT), sendo $11,1 \%$ (4/20) classificados no grau I; 61,1\% (22/33) no grau II; $19,4 \%$ (7/20) no grau III; e 8,3\% (3/3) no grau IV $\left(x^{2}=15,50 ; \quad \mathrm{P}=0,00143\right)$. Nenhum animal apresentou redução nesses valores.

A enzima hepática alanina aminotransferase (ALT) apresentou-se acima da faixa de normalidade em 32,9\% (25/76) dos animais. A creatinina sérica mostrou aumento em metade dos animais incluídos no estudo (50\% - 38/76). Observou-se aumento em fosfatase alcalina (FA) em $17,1 \%$ (13/76) dos animais avaliados e diminuição em 10,6\% (8/76). Os valores de proteínas séricas estavam aumentados em 40,8\% (31/76) dos animais. O valor de albumina estava aumentado em 22,4\% (17/76) dos animais e diminuído em 14,4\% (11/76). Houve aumento de globulina em 25\% (19/76) dos animais. A relação entre albumina e globulina apresentou diminuição em 15,8\% (12/76) dos gatos avaliados. Os valores de ureia mostraram-se 
aumentados em 29\% (22/76) dos animais (Tab. 2).

A análise citológica das amostras de lesões em cavidade oral demonstrou que a maioria dos animais portadores de CGE apresentou presença discreta de células descamativas $(65,8 \%$ - 50/76) $\left(x^{2}=133,13 ; \mathrm{P}=0,0001\right)$, ausência de leucócitos $\left(50 \%\right.$ - 38/76) $\left(x^{2}=60,76 ; \mathrm{P}=0,0001\right)$, presença discreta de fundo proteico $(77,6 \%$ - 59/76) $\left(x^{2}=199,9 ; \quad \mathrm{P}=0,0001\right)$, presença discreta de bactérias $\left(48,7 \%\right.$ - 37/76) $\left(x^{2}=73,20 ; \mathrm{P}=0,0001\right)$, ausência de bactérias espiraladas $(92,1 \%$ - 70/76) $\left(x^{2}=309,1 ; \mathrm{P}=0,0001\right)$ e ausência de Simonsiella spp. $\left(73,7 \%\right.$ - 56/76) $\left(x^{2}=176,2 ; \mathrm{P}=0,0001\right)$, embora a presença de Simonsiella spp. tenha sido mais frequente nos gatos incluídos no grau IV.

Tabela 1. Valores médios $(\overline{\boldsymbol{x}})$ e desvio-padrão $(\sigma)$ do leucograma de gatos domésticos portadores de complexo gengivite-estomatite (CGE), de acordo com o grau das lesões observadas na cavidade oral. Niterói, 2017

\begin{tabular}{|c|c|c|c|c|c|c|c|c|c|c|}
\hline Grau & $\mathrm{N}$ & $\begin{array}{c}\text { Leucócitos } \\
(\mu \mathrm{L}) \\
\bar{x} \pm \sigma\end{array}$ & $\begin{array}{c}\text { Basófilos } \\
\begin{array}{c}(\mu \mathrm{L}) \\
\bar{x} \pm \sigma\end{array}\end{array}$ & $\begin{array}{c}\text { Eosinófilos } \\
(\mu \mathrm{L}) \\
\bar{x} \pm \sigma\end{array}$ & $\begin{array}{c}\text { Bastonetes } \\
\quad(\mu \mathrm{L}) \\
\bar{x} \pm \sigma\end{array}$ & $\begin{array}{c}\text { Segmentados } \\
\begin{array}{c}(\mu \mathrm{L}) \\
\bar{x} \pm \sigma\end{array}\end{array}$ & $\begin{array}{l}\text { Linfócitos } \\
\qquad \begin{array}{l}(\mu \mathrm{L}) \\
\bar{x} \pm \sigma\end{array}\end{array}$ & $\begin{array}{l}\text { Monócitos } \\
\qquad \begin{array}{c}(\mu \mathrm{L}) \\
\bar{x} \pm \sigma\end{array}\end{array}$ & $\begin{array}{c}\text { Plaquetas } \\
(\mathrm{x} 1000 / \mu \mathrm{L}) \\
\bar{x} \pm \sigma\end{array}$ & $\begin{array}{l}\text { Proteínas } \\
\text { (cél./ } \mu \mathrm{L} \text { ) } \\
\bar{x} \pm \sigma\end{array}$ \\
\hline \multicolumn{2}{|c|}{ Referência } & $5.500-19.500$ & raros & $0-1.500$ & $0-300$ & $2.500-12.500$ & $\begin{array}{l}1.500- \\
7.000\end{array}$ & $0-850$ & $300-800$ & $5,4-7,8$ \\
\hline \multirow{2}{*}{ I) } & \multirow{2}{*}{20} & $14.220,00$ & 48,75 & $1.170,3$ & 0 & $8.392,4$ & $4.355,3$ & 246,95 & 364,55 & 7,56 \\
\hline & & $7.607,21$ & 185,62 & $1.217,57$ & 0 & $5.058,6$ & $2.584,74$ & 282,83 & 145,73 & 0,7 \\
\hline (II) & 33 & $15.254,55$ & 34,36 & $1.146,88$ & 0 & $9.910,64$ & $3.862,94$ & 304,73 & 392,73 & 8,1 \\
\hline \multirow{2}{*}{ (IV) } & \multirow{2}{*}{3} & $20.800,00$ & 0 & 763,33 & 0 & $16.240,67$ & $3.361,33$ & 434,67 & 324,67 & 8,3 \\
\hline & & $2,785,68$ & 0 & 385,45 & 0 & $1.868,91$ & $1.480,15$ & 293,78 & 62,83 & 0,5 \\
\hline
\end{tabular}

Tabela 2. Valores médios $(\overline{\boldsymbol{x}})$ e desvio-padrão $(\sigma)$ da bioquímica sérica de gatos domésticos portadores de complexo gengivite-estomatite (CGE), de acordo com o grau das lesões encontradas na cavidade oral. Niterói, 2017

\begin{tabular}{|c|c|c|c|c|c|c|c|c|c|}
\hline Grau & $\mathrm{N}$ & $\begin{array}{c}\text { ALT } \\
(\mathrm{U} / \mathrm{L}) \\
\bar{x} \pm \sigma\end{array}$ & $\begin{array}{c}\text { Fosfatase } \\
\text { Alcalina } \\
\text { (U/L) } \\
\bar{x} \pm \sigma\end{array}$ & $\begin{array}{c}\text { Proteínas } \\
\text { totais } \\
(\mathrm{g} / \mathrm{dL}) \\
\bar{x} \pm \sigma\end{array}$ & $\begin{array}{l}\text { Albumina } \\
\text { (g/dL) } \\
\bar{x} \pm \sigma\end{array}$ & $\begin{array}{l}\text { Globulina } \\
\text { (g/dL) } \\
\bar{x} \pm \sigma\end{array}$ & $\begin{array}{c}\text { Relação } \\
\text { A:G } \\
(\mathrm{g} / \mathrm{dL}) \\
\bar{x} \pm \sigma\end{array}$ & $\begin{array}{c}\text { Ureia } \\
(\mathrm{mg} / \mathrm{dL}) \\
\bar{x} \pm \sigma\end{array}$ & $\begin{array}{l}\text { Creatinina } \\
\text { (mg/dL) } \\
\bar{x} \pm \sigma\end{array}$ \\
\hline \multicolumn{2}{|c|}{ Referência } & $6-83$ & $25-93$ & $5,4-7,8$ & $2,6-3,3$ & $2,6-5,1$ & $0,5-1,2$ & $20-60$ & $0,8-1,5$ \\
\hline \multirow{2}{*}{ (I) } & \multirow{2}{*}{20} & 111,55 & 94,84 & 7,33 & 3,07 & 4,02 & 0,81 & 62,91 & 1,63 \\
\hline & & 93,42 & 104,81 & 0,76 & 0,33 & 0,96 & 0,22 & 20,56 & 0,67 \\
\hline (II) & 33 & 42,04 & 36,57 & 0,67 & 0,44 & 0,8 & 0,19 & 12,45 & 0,6 \\
\hline \multirow{2}{*}{ (III) } & \multirow{2}{*}{20} & 75,97 & 64,32 & 7,58 & 2,85 & 4,73 & 0,63 & 49,49 & 1,56 \\
\hline & & 52,95 & 44,71 & 0,47 & 0,42 & 0,71 & 0,17 & 12,12 & 0,42 \\
\hline \multirow{2}{*}{ (IV) } & \multirow{2}{*}{3} & 19,6 & 57,33 & 7,92 & 2,69 & 5,23 & 0,57 & 42,00 & 1,22 \\
\hline & & 9,6 & 41,45 & 0,62 & 0,78 & 1,23 & 0,24 & 12,68 & 0,06 \\
\hline
\end{tabular}

ALT - alanina aminotransferase.

Relação A:G - relação albumina-globulina.

\section{DISCUSSÃO}

A identificação dos fatores causadores de doenças orais recorrentes em gatos domésticos é de suma importância, uma vez que os sinais clínicos associados ao complexo gengiviteestomatite (CGE) são, na maioria das vezes, inespecíficos. Além disso, a determinação da gravidade da inflamação na cavidade oral dos gatos acometidos por CGE está diretamente relacionada ao manejo terapêutico e ao prognóstico. Assim, observou-se que as alterações mais frequentemente associadas ao CGE, como hiperemia da mucosa oral, halitose, perda de dentes, desconforto à manipulação da cavidade oral e ptialismo, mostraram-se mais evidentes nos graus mais avançados da doença (graus III e IV), o que também foi observado em outros estudos (Dokuzeylul e Kayar, 2016). 
No presente estudo, gatos machos, que conviviam com 11 a 20 animais no mesmo ambiente, foram os mais acometidos por CGE nos graus mais elevados da doença (graus III e IV). Embora não exista uma predisposição sexual (Healey et al., 2007), pode-se supor que o estresse causado pelo confinamento e pela convivência com muitos animais em ambientes restritos tenham influenciado nesses resultados.

A maior parcela da população de gatos com CGE com graus II e III foi constituída por animais adultos jovens e maduros, enquanto no grau I, os jovens e adultos jovens foram mais frequentemente acometidos. Já no grau IV, os três animais com lesões consideradas mais graves eram idosos ou geriatras. Assim, quanto mais velhos eram os gatos, maior foi a gravidade de lesão em cavidade oral observada (Wolf, 2007; Dokuzeylul e Kayar, 2016).

A maioria da população acometida por CGE era sem raça definida (SRD), castrada e vivia confinada, alimentada à base de alimento seco e úmido e em horários predeterminados pelos tutores, e, embora não haja relação entre a raça (Niza et al., 2004; Lyon, 2005; Healey et al., 2007), o estado reprodutivo e a presença de lesões em cavidade oral, supõe-se que o fato de os animais viverem confinados e, portanto, submetidos a um manejo alimentar mais restrito ou não adequado, tenha influenciado na presença e gravidade das lesões observadas na cavidade oral desses animais. Da mesma forma, o número de animais com os quais os gatos convivem pode influenciar na gravidade das lesões em cavidade oral (Dokuzeylul e Kayar, 2016), uma vez que a liberação do cortisol altera a função imunológica do organismo, podendo favorecer o surgimento de infecções e, até mesmo, causar alterações no trato gastrointestinal, levando ao aparecimento de úlceras na cavidade oral.

A maioria dos animais com CGE apresentou escore de condição corporal (ECC) 3 e normofagia, indicando que, mesmo na presença de inflamação e lesões na cavidade oral, os animais mantêm seus hábitos alimentares. Já a presença de episódios de vômitos foi observada somente nos gatos incluídos nos graus II, III ou IV, sendo ainda proporcionalmente maior à medida que a gravidade das lesões em cavidade oral se intensificava, o que sugere que quanto maior a gravidade das lesões, maiores as chances de os gatos manifestarem vômitos, sendo esse um sinal de relevância clínica nos casos de CGE.

Com relação ao eritrograma, não se observou diferença estatística significativa nos resultados dos gatos incluídos nos diferentes graus de lesão em cavidade oral, e isso indica que gatos portadores de CGE não apresentam alterações no eritrograma que possam auxiliar no diagnóstico da afecção.

Já o aumento nos níveis de proteínas plasmáticas totais (PPT) pressupõe uma origem imunológica (Harvey, 2006; Wolf, 2007; Allemand et al., 2013) devido a uma maior produção de imunoglobulinas, e esse aumento pode se refletir nos valores de PPT. Dessa forma, o aumento nos níveis de PPT deve ser considerado como indício da presença de lesões em cavidade oral de gatos domésticos, mesmo que nos graus mais leves de gravidade (I e II).

Quanto à bioquímica sérica, as enzimas hepáticas alanina aminotransferase (ALT) e fosfatase alcalina (FA) mostraram aumento estatístico significativo entre os gatos com diferentes graus de lesões em cavidade oral. Interessante notar que esse aumento foi mais significativo nos gatos com CGE menos graves (graus I e II). Assim, sugere-se que essas enzimas, quando aumentadas, possam ser utilizadas como indicadores mais precoces de presença de CGE.

O aumento da creatinina foi observado em $50 \%$ dos gatos incluídos no estudo, sendo a maioria classificada no grau II. Esse aumento pode indicar a presença de lesão renal ou pode estar relacionado à desidratação. Uma vez que os gatos com diagnóstico de doença renal crônica (DRC) ou injúria renal aguda (IRA) não foram incluídos no estudo, sugere-se que o aumento de creatinina se deveu somente à presença de CGE, que determinou diminuição do apetite e ingestão de água, o que acarretou uma desidratação subclínica. Vale ressaltar que $29 \%$ dos animais também apresentaram aumento de ureia, fato que permite deduzir que essas alterações se deveram à presença da desidratação relacionada à CGE ou, ainda, que esses gatos deverão ser novamente avaliados quanto à possível presença de DRC subclínica.

Interessante notar que, apesar de a literatura recomendar que o nível de proteínas séricas, 
juntamente com a avaliação da globulina, deva ser sempre avaliado quando se suspeita de CGE, visto que é frequente encontrar aumento nesses dois parâmetros nos animais portadores da afecção (Wolf, 2007; Allemand et al., 2013), não se observou relação entre o aumento das proteínas séricas ou da relação albuminaglobulina e o grau de gravidade das lesões em cavidade oral. A maioria dos animais não apresentou aumento nos valores de globulina, tampouco de albumina, o que indica que as proteínas plasmáticas totais, em vez das proteínas séricas, sejam um parâmetro que, quando aumentado, deva ser levado em consideração nos gatos portadores de CGE, possivelmente relacionado ao aumento de fibrinogênio ou mesmo nos casos de desidratação.

A análise citológica das amostras de lesões em cavidade oral dos gatos com diferentes graus de CGE demonstrou que a presença de Simonsiella spp. foi mais frequente nos gatos incluídos no grau IV e, embora a literatura afirme que esta é uma bactéria frequentemente encontrada na cavidade oral, sem valor patológico (Bernreuter, 2009), é possível que, nos animais com graus mais elevados de lesão em cavidade oral, devido à alteração sofrida pelo sistema imune, a bactéria encontre um ambiente mais propício para se desenvolver, sendo mais facilmente observada nas lâminas de citologia. Em razão do reduzido número de animais incluídos nesse grupo, recomenda-se que mais estudos com o uso da citologia, que é considerada um método pouco invasivo e útil para lesões de orofaringe (Bernreuter, 2009; Bonfanti et al., 2015), sejam conduzidos como auxílio para a classificação dos graus de gravidade das lesões observadas em gatos portadores de CGE e prognóstico.

\section{CONCLUSÕES}

A população de gatos domésticos com diferentes graus de lesão em cavidade oral foi composta predominantemente por machos, castrados, adultos, sem raça definida e com estilo de vida confinado, e os principais sinais clínicos associados à gravidade da inflamação na cavidade oral foram halitose, ptialismo, hemorragia bucal, úlcera na parte superior dos lábios, perda dentária e desconforto à manipulação da cavidade oral. A maioria dos gatos domésticos portadores de CGE, independentemente do grau de gravidade de lesão em cavidade oral, apresentou bom estado geral, escore de condição corporal (ECC) 3, normofagia, pelame sem alterações e ausência de êmese; leucocitose e aumento das proteínas plasmáticas totais (PPT) foram observados nos resultados dos exames laboratoriais de gatos domésticos portadores de CGE, independentemente do grau de gravidade de lesão em cavidade oral; gatos domésticos portadores de CGE menos grave (grau I) apresentaram um aumento maior nos níveis de alanina aminotransferase (ALT) e de fosfatase alcalina (FA). Os resultados da análise citológica das amostras de lesões em cavidade oral de gatos domésticos portadores de CGE mostraram que as células encontradas não diferem significativamente conforme o grau de lesões aumenta.

\section{REFERÊNCIAS}

ABREU, A.C.A. Complexo gengivite-estomatitefaringite dos felinos: revisão de literatura. 2012. 38f. Monografia (Especialização em Clínica Médica de Pequenos Animais) - Universidade Federal Rural do Semi-Árido, Mossoró, RN.

ALLEMAND, V.C.; RADIGHIERI, R.; BEARL, C.A. Gengivite-estomatite linfoplasmocitária felina: relato de caso. Rev. Educ. Cont. Med. Vet. Zootec. CRMV-SP. v.11, p.24-29, 2013.

BERNREUTER, D.C. A orofaringe e as tonsilas. In: COWELL, R.L.; TYLER, R.D.; MEINKOTH, J.H.; DENICOLA, D.B. Diagnóstico citológico e hematologia de cães e gatos. 3.ed. São Paulo: MedVet, 2009. 476p. cap.8, p.138-140.

BONFANTI, U.; BERTAZZOLO, W., GRACIS, M. et al. Diagnostic value of cytological analysis of tumours and tumour-like lesions of the oral cavity in dogs and cats: a prospective study on 114 cases. Vet. J., v.205, p.322-327, 2015.

COLLIARD, L.; PARAGON, B.M.; LEMUET, B. et al. Prevalence and risk factors of obesity in an urban population of healthy cats. J. Feline Med. Surg., v.11, p.1135-140, 2009.

DOKUZEYLUL, B.; KAYAR, A. Prevalence of systemic disorders in cats with oral lesions. Vet. Med., v.61, p.219-223, 2016. 
GERALDO JUNIOR, C.A. Avaliação da ocorrência do calicivirus felino e do herpesvirus felino tipo $1 \mathrm{em}$ gatos com gengivite-estomatite crônicas naturalmente infectados pelo vírus da imunodeficiência felina. 2010. 83f. Dissertação (Mestrado) - Universidade de São Paulo, São Paulo, SP.

HARLEY, R.; GRUFFYDD-JONES, T.J.; DAY, M.J. Immunohistochemical characterization of oral mucosal lesions in cats with chronic gingivostomatitis. J. Comp. Pathol., v.144, p.239-250, 2010.

HARVEY, C.E. Cavidade Oral. In: CHANDLER, E.A.; GASKELL, C.J.; GASKELL, R.M. Clínica e terapêutica em felinos. 3.ed. São Paulo: Roca, 2006. cap.15, p.312-319.

HEALEY, K.A.E.; DAWSON, S.; BURROW, $\mathrm{R}$. et al. Prevalence of feline chronic gingivastomatitis in first opinion veterinary practice. $J$. Vet. Med. Surg., v.9, p.373-381, 2007.

LYON, K.F. Gingivostomatitis. Veterinary Clinics: Small Animal Practice, v.35, p.891-911, 2005.

MATILDE, K.S.; LOURENÇO, M.L.G.; ZAHN, F.S.; MACHADO, L.H.A. Complexo gengivite estomatite felina: revisão de literatura. Rev. Vet. Zootec., v.20. p.160-170, 2013.

MILELLA, L. Dental disorders and their management. In: HARVEY, A.; TASKER, S. (Eds.). BSAVA Manual of feline practice: $a$ foundation manual. Gloucester: BSAVA, 2014. p.324-334.
NIZA, M.M.R.E.; MESTRINHO, L.A.; VILELA, C.L. Gengivo-estomatite crónica felina - um desafio clínico. Rev. Port. Ciênc. Vet., v.99, p.127-135, 2004.

SOUTHERDEN, P.; GORREL, C. Treatment of a case of refractory feline chronic gingivostomatitis with feline recombinant interferon omega. J. Small Anim. Pract., v.48, p.104-106, 2007.

VENTURINI, M.A.F.A. Estudo retrospectivo de 3055 animais atendidos no ODONTOVET® (Centro Odontológico Veterinário) durante 44 meses. 2006. 104f. Dissertação (Mestrado) Universidade de São Paulo, São Paulo, SP.

VOGT, A.H.; RODAN, I.; BROWN, M. et al. Feline life stages guidelines. J. Am. Anim. Hosp. Assoc., v.46, p.70-85, 2010.

WATERS, L.; HOPPER, C.D.; GRUFFYDDJONES T.J.; HARBOUR, D.A. Chronic gingivitis in a colony of cats infected with feline immunodeficiency virus and feline calicivirus. Vet. Rec., v.132, p.340-342, 1993.

WINER, J.N.; ARZI, B.; VERSTRAETE, J.M. Therapeutic management of feline chronic gingivostomatitis: a systematic review of the literature. Front. Vet. Sci., v.3, p.1-10, 2016.

WOLF, A.M. Gingivitis, stomatitis and other oral lesions in cats. DVM360, Kansas, USA, 2008. Available in <http://veterinarycalendar.dvm360.com/gingiviti s-stomatitis-and-other-oral-lesions-proceedings0>. Accessed in: 15 Jun. 2015. 